\title{
ALTERNATIVE DEVICES IN AIRWAY VISUALIZATION
}

\author{
Branka Maldini1 ${ }^{1,2}$, Iljaz Hodžović ${ }^{3}$ and Tatjana Goranović ${ }^{2,4}$ \\ ${ }^{1}$ Department of Anesthesiology and Intensive Medicine, Sestre milosrdnice University Hospital Center, \\ Zagreb; ${ }^{2}$ School of Medicine, Josip Juraj Strossmayer University, Osijek, Croatia; ${ }^{3}$ Anaesthesia, Intensive Care \\ and Pain Medicine, Wales School of Medicine, Cardiff University, Cardiff, United Kingdom; ${ }^{4}$ Department \\ of Anesthesiology and Intensive Medicine, University Department for Tumors, Sestre milosrdnice University \\ Hospital Center, Zagreb, Croatia
}

\begin{abstract}
SUMMARY - The Macintosh laryngoscope has been the most widely used device for intubation since its invention by Foregger in the 1940s. Recently, video and optic laryngoscopy assisted tracheal intubation has been used widely in patients with difficult airways. Their routine use, however, is not widely practiced. This review will summarize some of the newly available devices to assist tracheal intubation, with their advantages and disadvantages when compared with conventional laryngoscopes. It also presents the reasons to support their use in both elective and emergency airway management.
\end{abstract}

Key words: Laryngoscopes; Fiber Optic Technology; Video Recording; Intubation, Intratracheal

\section{Introduction}

Despite many advances in patient safety, endotracheal intubation remains a specialized learned skill, and difficult endotracheal intubation remains an important adverse event ${ }^{1,2}$. Direct laryngoscopic tracheal intubation is an effective method to secure the airway ${ }^{1}$. However, it is not an easy skill to acquire and maintain without regular practice, and the technique requires experienced professionals. Successful direct laryngoscopy requires alignment of the oral, pharyngeal and laryngeal axes. Since the appearance of the Macintosh/Miller rigid laryngoscopes in the $1940 s^{1}$, attempts to optimize laryngoscopy have been largely limited by the intubating conditions, optimal patient positioning and available technology. Despite careful airway assessment, direct laryngoscopy occasionally yields unexpectedly poor laryngeal views ${ }^{2}$.

\footnotetext{
Correspondence to: Prof. Branka Maldini, $M D, P h D$, Department of Anesthesiology and Intensive Care, Sestre milosrdnice University Hospital Center, Vinogradska c. 29, HR-10000 Zagreb, Croatia

E-mail: branka.maldini@gmail.com

Received May 13, 2015, accepted September 20, 2015
}

Such difficulties, even if ultimately successful, may result in multiple laryngoscopic attempts and be associated with significant hemodynamic disturbance, oxygen desaturation, sore throat, airway injury, and dental damage (the latter accounting for one-third of all confirmed or potential anesthetic claims) ${ }^{2}$, intensive care unit admission, neurologic impairment, and death ${ }^{3}$. Consequently, several alternative techniques have developed over time to overcome some of the deficiencies of the 'line of sight' laryngoscopy technique: intubation through the intubating laryngeal mask airway, use of different laryngoscope blades, use of gum-elastic bougie or malleable stylet, retrograde intubation, and blind oral or nasal intubation. In contrast to direct laryngoscopy, the appearance of optical fibers ushered in the era of the flexible fiberscope and rigid indirect laryngoscopes that allowed us to 'see around the corner' without trying to convert the corner to straight line ${ }^{4}$. Video-guided intubation makes better anatomical sense ${ }^{1}$. A skill set to be developed, enhanced and assessed for successful visualization of the larynx would include the use of both rigid and flexible endoscope. Broad classification of the devices used for airway visualization is shown in Table 1. 
Table 1. Classification of intubating derices based on the airway visualization technique

\section{Direct laryngoscopes}

Straight blade (e.g., Miller laryngoscopes)

Curved blades (e.g., Macintosh laryngoscopes)

Blades with articulating tips (e.g., McCoy

laryngoscope)

\section{Indirect intubating devices}

Video and optic laryngoscopes (e.g., C-MAC Storz, Airtraq)

Fiberoptic stylets (e.g., Bonfils fiberscope)

Flexible fiberoptic devices (Storz intubation flexible fiberscope)

The aim of this article is to provide a topical review of the literature on indirect rigid and flexible fiberoptic intubation devices as alternative methods in the visualization and management of difficult airway. Each particular device features may offer advantages or disadvantages, depending on the situation the anesthesiologist has to deal with.

\section{Table 2. Advantages of fiberoptic intubation}

The sniffing position is not required

- Intubation feasible even under extreme positioning of the patient

- Maximum patient safety (intubation of conscious patient)

- The best devices for inspecting the airway (even in patient with small mouth opening)

- Management of the predicted difficult airway

- Management of the unpredicted difficult airway (difficult or impossible laryngoscopy, respiratory emergencies, as well as the unanticipated can ventilate but cannot intubate scenario)

- Intubation with a fiberoptic scope is possible through the LMA (especially if the LMA was used to rescue failed intubation attempts)

- Reduced risk of aspiration (spontaneously breathing patients require no mask ventilation, maintain protective reflexes)

- Absolute control of tube position

- Reduce the risk of pharmacological side effects

- Suction and pulmonary toilet can be performed
Table 3. Problems encountered during fiberoptic intubation

- Requires practice (at least 10 fiberoptic intubations on anesthetized patients and 15-20 intubations on awake patients with normal anatomy ${ }^{2}$

- Impaired view due to blood, mucus, secretions and edema

- Pronounced stress reaction, laryngospasm due to insufficient topical anesthesia

- A good view of the glottis is not always followed by successful intubation (a problem contributed to by narrow angle of view from the tip of the fiberoptic scope)

\section{Methods}

Indirect rigid and flexible fiberoptic intubation devices that have been used by the authors are reviewed in this article. A review of citations from PubMed was conducted without time limit until March 2015. Fulltext articles were retrieved of any citations that were considered potentially relevant and were included.

\section{Device video and optic variability}

Recent development of smaller and more reliable video cameras has revolutionized the design of laryngoscopes and the process of endotracheal intubation. The term video laryngoscopy defines a broad range of devices, distinct from fiberoptic bronchoscopes, in which a video camera is used in place of line-of-sight visualization to accomplish endotracheal intubation. Over a dozen laryngoscopes are marketed currently ${ }^{4-6}$. A video laryngoscope collects electronically processed images with a camera attached at its tip. Images of the airway are observed on a monitor attached ${ }^{4}$. Optical laryngoscopes are similar devices based on optic techniques (fiberoptic cable and lens) and the glottis is observed through a viewfinder ${ }^{5}$. Each model of video laryngoscope has its own unique strengths, weakness and best applications. However, failure can occur during any intubation attempt and the utility of video laryngoscopy must be considered as an alternative intubation device when direct laryngoscopy fails 5 . After failure of initial direct laryngoscopy, morbidity has been shown to increase when more than two attempts are made at laryngoscopy during emergency intubations performed beyond the operating room ${ }^{7}$. 

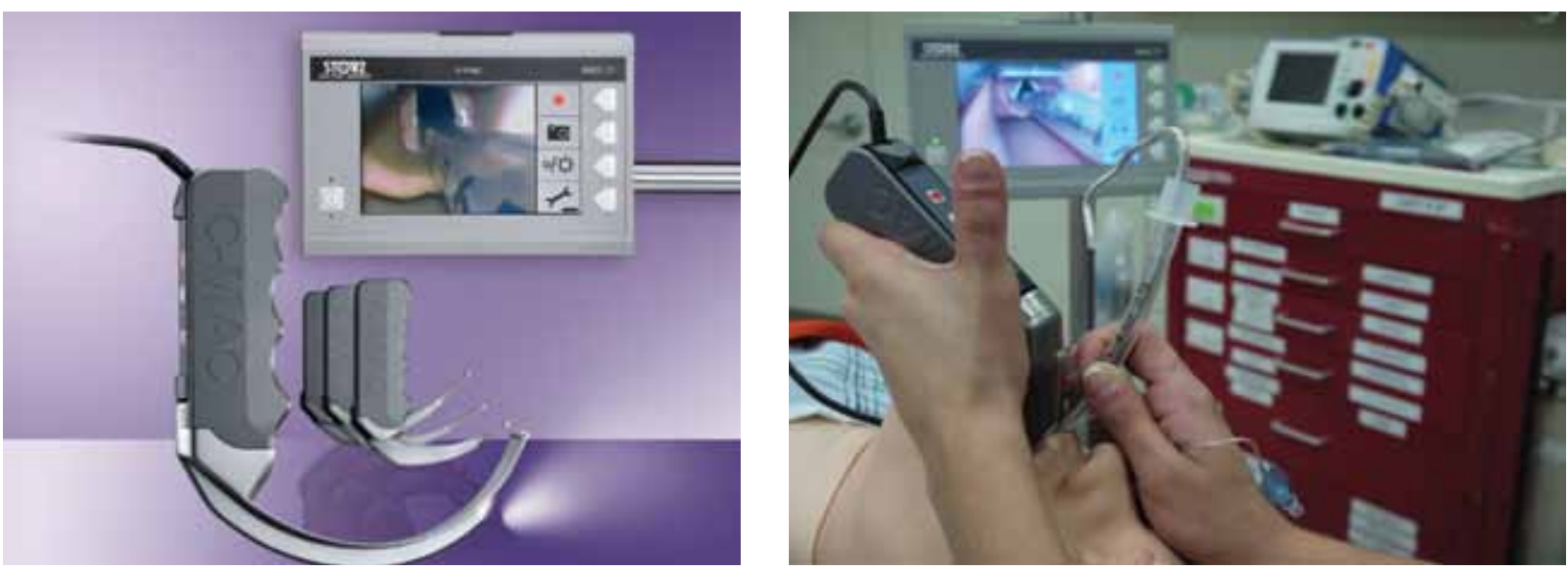

Fig. 1. Example of Macintosh type video laryngoscope: the Storz $C-M A C$ video laryngoscope.

The Difficult Airway Society of the United Kingdom suggests in their failed intubation guideline that a provider makes no more than two attempts with the same device before moving on to an alternative device, with the maximum number of laryngoscopy attempts limited to four when managing unexpected difficult airway of a starved patient ${ }^{8}$. In addition to the low success rates of multiple intubation attempts, complications such as airway trauma, hypoxia, tachycardia, increase in blood pressure and intraocular pressure, aspiration, and cardiac arrest may arise $\mathrm{e}^{7,8}$.

Available data suggest that the new intubation equipment may play a crucial role in advanced air-

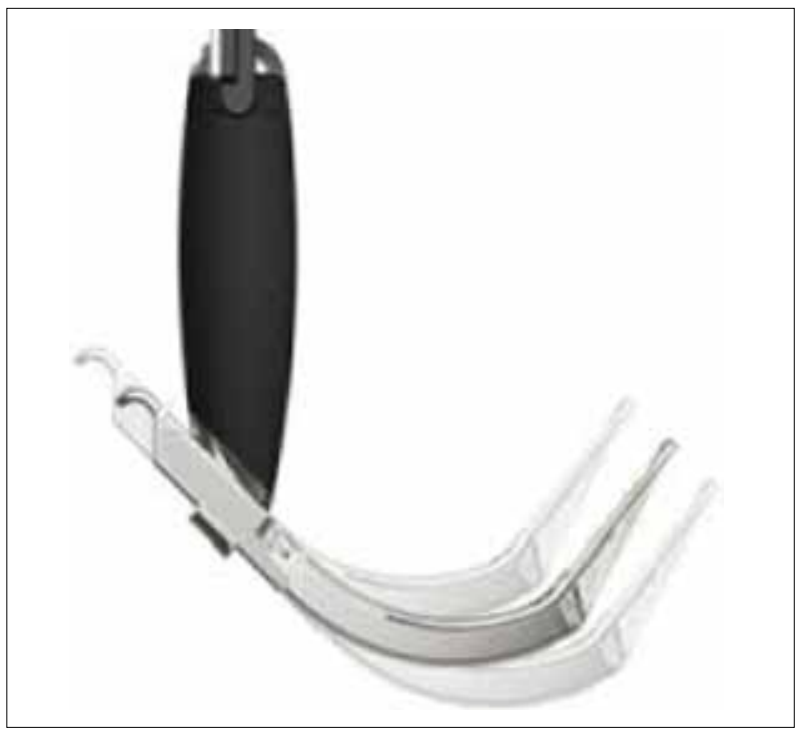

Fig. 2. Examples of angulated blade video laryngoscope: the McGrath video laryngoscope and Storz D-blade video laryngoscope.

way management ${ }^{9-11}$. Recently, video and optic laryngoscopic assisted tracheal intubation has been used widely in patients with difficult airways or as rescue in field intubation attempts. Their routine use, however, is not widely practiced. Video laryngoscopes are now incorporated into airway algorithms for awake intubation in the predicted difficult airway as well as unpredicted difficult intubation, following induction of general anesthesia ${ }^{12}$. Examples of different types of video laryngoscope are provided in Figures 1-3.

New intubation video and optic laryngoscopes can be categorized as follows (Fig. 4):

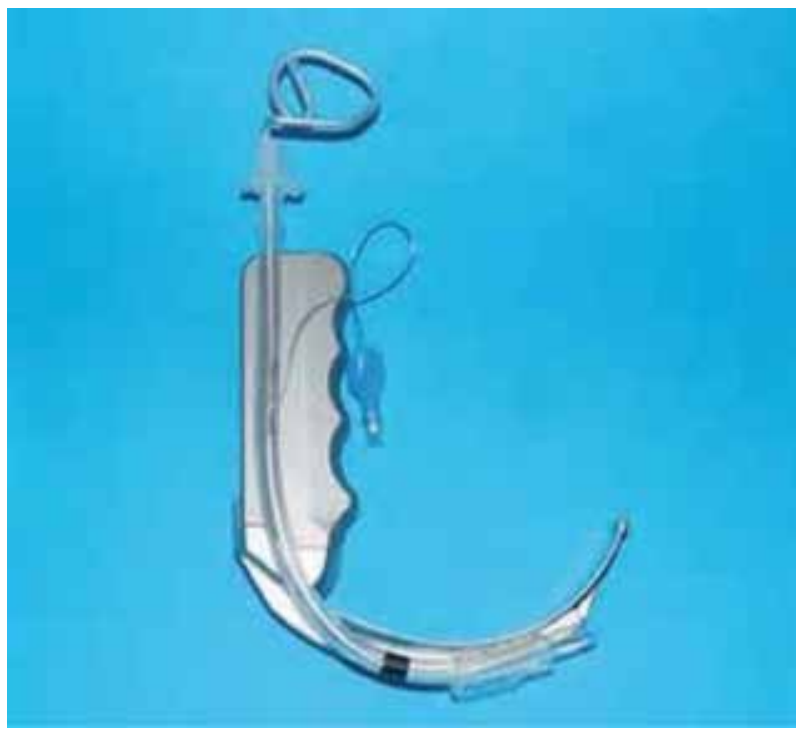



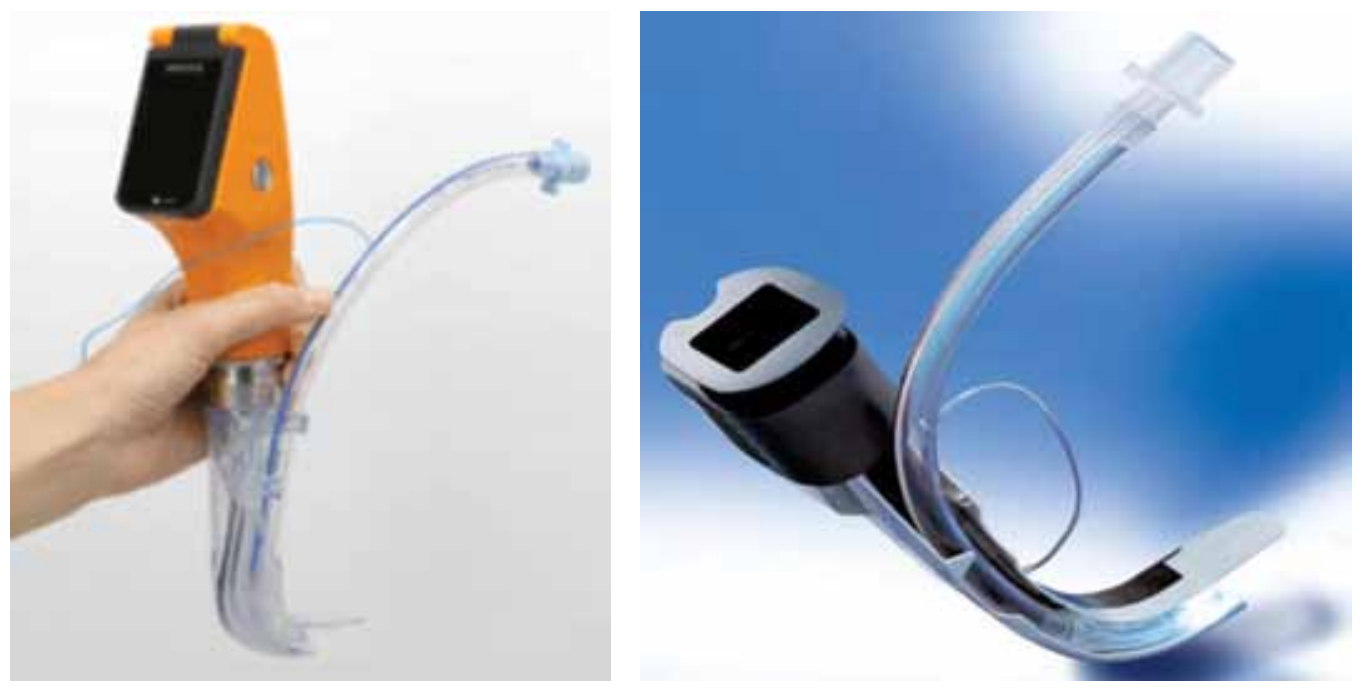

Fig. 3. Examples of video laryngoscopes with a tube channel (channeled video laryngoscopes): the Airtraq and Pentax AWS system (Airway Scope).

\section{Macintosh like blade rigid indirect optical devices}

Representative laryngoscopes include the Storz V-MAC/C-MAC video laryngoscope (Karl Storz, Tuttlingen, Germany) and McGrath MAC (Aircraft Medical, Edinburgh, Scotland). The video laryngoscopes have a Macintosh-type blade similar to that of standard laryngoscopes; the difference lies in the inclusion of a camera. The blade is inserted into the oral cavity using the standard direct laryngoscopic technique, and the glottis can then be seen either under direct vision or on a video screen ${ }^{13}$. The endotracheal

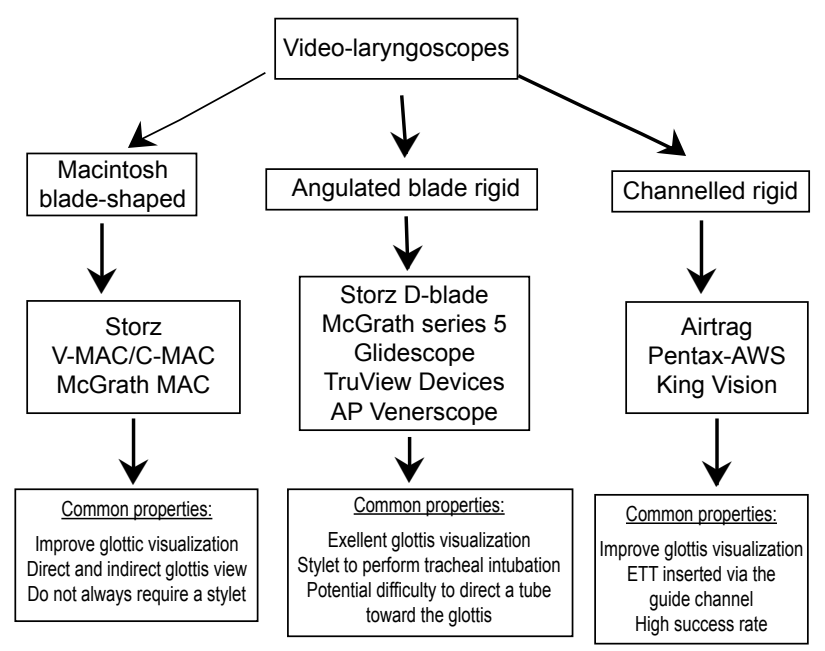

Fig. 4. Classification of video laryngoscopic devices based on the method of use and blade shape. tube (ETT) is inserted in much the same way as with direct laryngoscopy. These devices most of the time require a stylet to aid tracheal tube placement ${ }^{12,13}$.

\section{Angulated blade rigid indirect optical devices}

Representative laryngoscopes include the Storz Dblade (Karl Storz), McGrath series 5 (Aircraft Medical), Glidescope (Verathon Medical, Bothell WA, USA), TruView Devices (Truphatek International Limited, Netanya, Israel), AP Venerscope (Intavent Direct, Maidenhead, UK). The video laryngoscopes have an angulated blade which is characterized by a sharper curve than the Macintosh blade. The curvature of the blade allows clear view of the glottis on the video screen with minimal flexion or extension of the patient's head and neck, but direct visualization is usually not possible14.These video laryngoscopes are normally introduced in the middle of the oral cavity without tongue displacement. They glide along the palate and the posterior pharynx until the tip of the blade reaches the vallecula or the posterior aspect to the epiglottis if the epiglottis obscures the glottis14. Contrary to the Macintosh-type blade, the ETT has to be introduced 'around the corner' and should be mounted on a pre-shaped $60^{\circ}$ angle stylet to match the blade curvature. A limitation of this type of video laryngoscope is the potential difficulty to direct the tube toward the glottis despite obtaining clear view. These devices markedly improve glottic visualization 

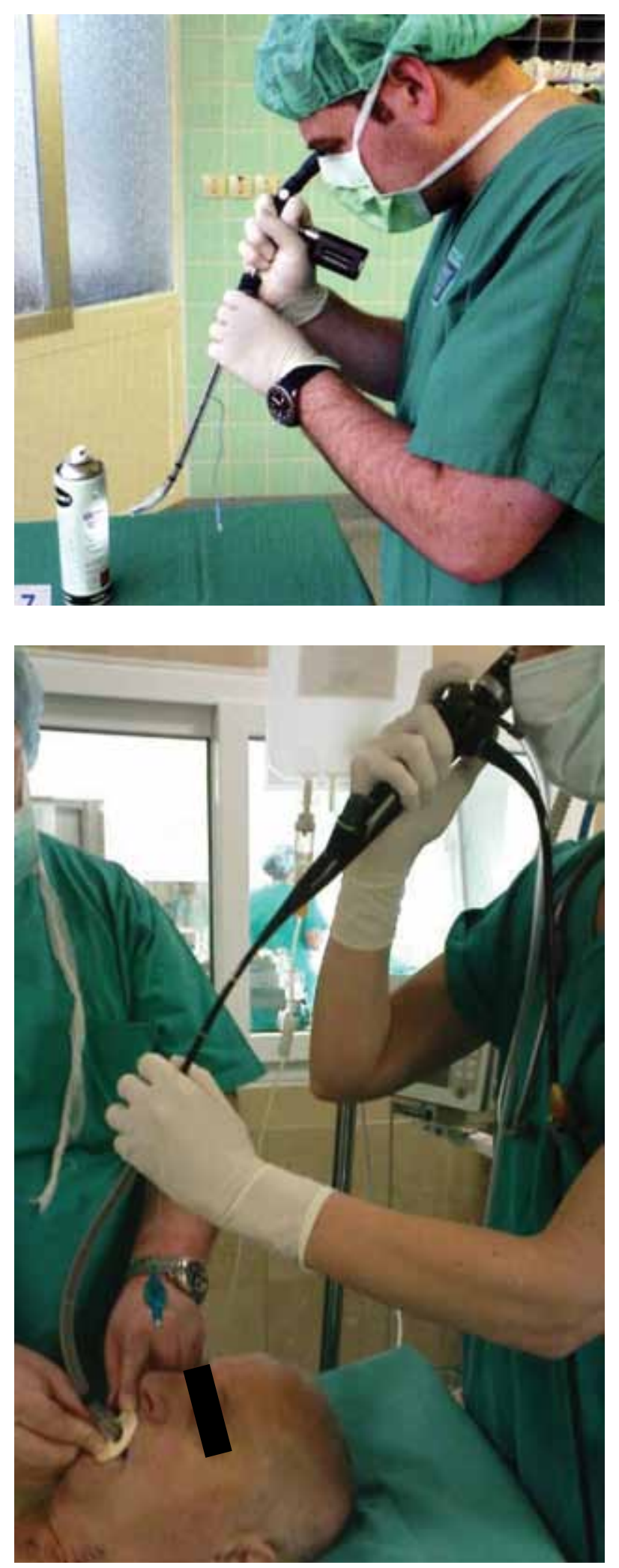

Fig. 6. Flexible intubation video endoscopes.

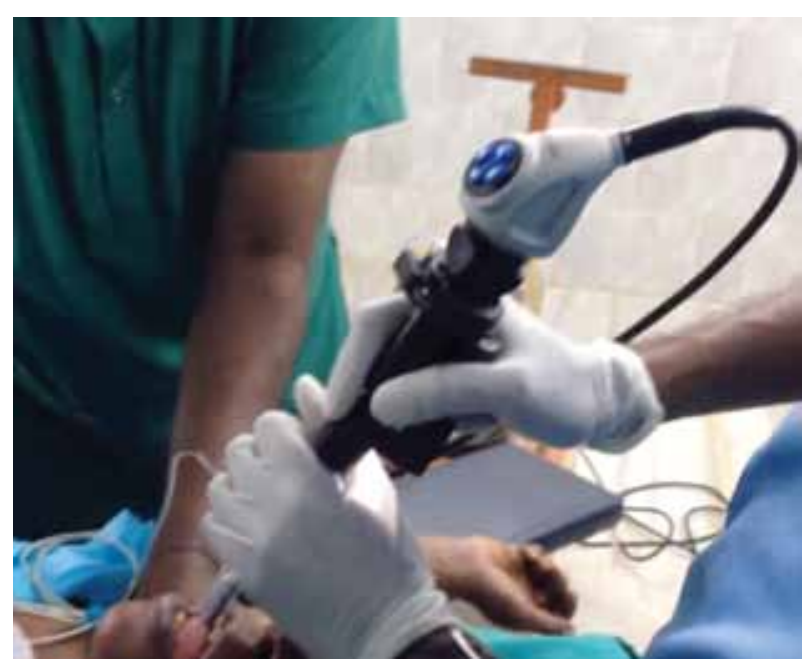

Fig. 5. Examples of optical stylets:

B

A) Bonfils intubation endoscopes.

B) Levitan optical stylet

with minimal patient head flexion and neck extension10.

\section{Channeled blade rigid indirect optical devices}

Representative laryngoscopes include the Airtraq (Prodol, Vizcaya, Spain), Pentax-Airway Scope (Pentax-AWS, Ambu Glen Burnie MD, USA), King Vision (King System, Noblesville, USA). The video laryngoscopes have an anatomically shaped blade and a guide channel that directs the endotracheal tube towards the glottis. These video laryngoscopes have a screen mounted on their handle. With these instruments, the ETT is preloaded into the guide channel; the video laryngoscope is then inserted along the midline of the patient's mouth without displacing the tongue laterally and is advanced slowly until the epiglottis is viewed ${ }^{10}$. The tip of the blade is positioned posteriorly to the epiglottis, directly elevating in order to visualize the vocal cords. It is important to place the glottic opening in the center of the monitor. The ETT is then inserted into the trachea via the guide channel ${ }^{13}$. The channeled blade laryngoscopes cannot be inserted in patients with reduced mouth opening. They generally have a larger and more angulated blade when compared to the nonchanneled blade video laryngoscopes. Also, the angle of force applied with the laryngoscope is more perpendicular to the cervical spine, which may reduce cervical spinal displacement during laryngoscopy ${ }^{13,14}$. All are 
designed for oral endotracheal intubation using a standard ETT. The view screens are generally small and attached directly to the device, making the laryngoscopes highly portable.

Many of the new intubation devices have been used successfully to perform awake intubation ${ }^{15}$. Combined use of a flexible optical scope and other new devices has also been described ${ }^{16}$.

\section{Limitations and complications}

Many devices using indirect laryngoscopy with video technology are documented to provide a good view of the glottis, even in difficult airway ${ }^{6}$. However, a good view of the glottic opening does not always ensure easy passage of the tracheal tube when non lineof-sight techniques are used. Despite clear visualization of the glottis, the insertion and advancement of the ETT with video laryngoscopes may occasionally fail ${ }^{13,14}$. The inability to deliver the ETT to a visualized larynx is both frustrating and largely avoidable. In order to achieve successful intubation with video laryngoscopes, the operator should follow each manufacturer's guidelines with respect to endotracheal tube pre-shaping and proper maneuvers when resistance to advancement of the ETT occurs. Further maneuvers and adjuncts may be required to advance the ETT, such as cricoid pressure, slight withdrawal of the stylet, rotating the ETT, and use of gum elastic bougie ${ }^{10}$. When a styletted tracheal tube is inserted blindly, while looking at the screen or in the eyepiece of the new device, there is a risk of injury to the palatal arch and other structures9. Undoubtedly, all new intubation equipment has the potential for complications associated with its use, although available data allow little comparison among devices in this regard. Auscultation and capnography must be performed as additional test of appropriate tube placement.

Key points: The future of video laryngoscope is promising. Is one model of video laryngoscope 'the best'? Probably not. None of the models appears uniformly superior to another, and none is $100 \%$ successful. Studies show that video laryngoscopes are associated with better glottic visualization, a higher success rate for difficult airways, and a faster learning curve, resulting in a higher success rate for intubations by novice physicians, and minimal head or neck manipu- lation ${ }^{9,10}$. Thus, unanticipated difficult intubations may be less frequent if video laryngoscopy is used as the first-line approach. In adult patients with an 'easy airway', direct laryngoscopy was found to be faster and cheaper than intubation using new devices ${ }^{10,11}$. Despite different shapes and characteristics of video laryngoscopes, there is little information about which video laryngoscope design could be more advantageous in various clinical situations. Perhaps the question of most clinical relevance is: which devices are successful in the event of a difficult or failed intubation attempt with a traditional direct laryngoscopy? ${ }^{30}$.

\section{Optical stylet devices}

Stylets are rigid or semi-rigid rods that carry light and video/fiberoptic bundles. A number of optical stylets have been introduced into clinical practice since $1995^{17}$. Most of these devices are rigid with predetermined shape and length. There are, however, examples of optical stylets that are semi-rigid, allowing for some preintubation shaping, or have steerable tip with rigid body ${ }^{18}$. The Bonfils Retromolar Intubating endoscope (Karl Storz, Tuttlingen, Germany; http:// www.karlstorz.com) was one of the first optical stylets introduced into clinical practice and may be considered a gold standard device for optical stylets. It comes in adult sizes and pediatric stylet (Brambrink intubation endoscope, Karl Storz GmbH \& Co.KG, Tuttlingen, Germany). The Bonfils intubation endoscope was invented as an optical device over 25 years ago to permit retromolar intubation in patients with limited mouth opening ${ }^{19}$. The insertion rod is available in 2-, $3.5-$, and $5-\mathrm{mm}$ outside diameters, and has a $1.2-\mathrm{mm}$ working channel for continuous oxygen flow. The insertion rod is bent at a $40^{\circ}$ angle at the distal end, and the optics provide a $110^{\circ}$ view angle that includes view of the distal tip of the endotracheal tube, which is mounted over the insertion rod and then slide of the rod and the glottis. Bonfils is introduced via retromolar approach. Guided by the operator's right hand, the Bonfils is advanced underneath the epiglottis and guided through the glottic aperture until the tracheal rings can be identified. The ETT can then be inserted into the trachea under direct vision (Fig. 5). The retropharyngeal space can be improved by performing chin lift with the left hand or inserting a Macintosh blade simultaneously ${ }^{19}$. 
There is significantly less movement of the upper cervical spine during intubation with the Bonfils as compared with the Macintosh laryngoscope ${ }^{20}$. $\mathrm{Ru}-$ dolph et al. compared cervical spine movement and time to best laryngeal view with the Bonfils intubation stylet and the Macintosh laryngoscope in 20 patients undergoing elective general anesthesia. The Bonfils improved Cormack and Lehane views in all patients to grade 1 and caused significantly less cervical spine motion during laryngoscopy and intubation. Compared to flexible fiberoptic bronchoscopy, it takes less time to prepare in the event of unanticipated difficult intubation, and it is also cheaper ${ }^{20}$.

Problems encountered during Bonfils intubation: as with other devices with a fiberoptic lens, Bonfils has similar disadvantages such as fogging or obscured view by blood or secretions. Its rigid nature does not allow for nasotracheal intubation. Bonfils requires prior training for successful intubation.

Key points: Video stylet device may be advantageous for oral endotracheal intubation when mouth opening is limited or for the management of patients with other cervical spine pathology to prevent cord damage. Compared to flexible fiberoptic bronchoscopy, it takes less time to prepare in the event of unanticipated difficult intubation ${ }^{20}$, and it is also cheaper. Bonfils is rather large, and the optic may be subject to secretions and fogging. It requires a substantial learning curve. This device appears to be most suited to special situations and use by operators willing to practice and attain sufficient skill in their use.

\section{Flexible Fiberoptic Intubation}

There are many brands of flexible fiberoptic endoscopes on the market, e.g., Karl Storz (Tuttlingen, Germany), Olympus (America Inc., Center Valley, PA, USA) and Pentax (Pentax Canada Inc., Ontario, Canada). They come in many sizes with different diameters suitable for adults and children. Most intubation fiberscopes have approximately $60 \mathrm{~cm}$ working length and distal maneuverable tips that deflect $140^{\circ}$ up and down (Fig. 6). Flexible fiberscope comes with a light source and suction channel that can be used for administration of local anesthetic and/or oxygen insufflations. Images can be projected on a monitor screen or viewed via the eyepiece ${ }^{2}$.
Early detection of intubation difficulties is one of the most significant tasks of the anesthesiologist and should be assessed preoperatively to maximize the quality of procedural safety measures. If the patient is likely to prove difficult to intubate, fiberoptic intubation can considerably reduce the risk of hypoxia: it allows the anesthesiologist to conduct the procedure in the conscious, spontaneously breathing patient using no more than topical anesthesia and mild sedation. However, since fiberoptic-guided intubation can be regarded as a safe technique only on the condition that there is sufficient and regular practice, both theoretical and practical training and continuing education of anesthesiologists are essential.

Flexible fiberoptic bronchoscopes are particularly useful in awake intubation, when the airway is adequately anesthetized minimizing patient discomfort. The success of flexible fiberoptic assisted intubation requires appropriate planning and patient preparation. As fiberoptic bronchoscopy requires a clear visual pathway, administration of antisialogogue prior to the start of the procedures is recommended. If the patient is not at risk of aspiration, the airway should be anesthetized. This can be achieved by various methods such as the superior laryngeal nerve block, transtracheal nerve block or topical lignocaine spray. The patient's nasal passages should be treated with a topical vasoconstrictor to shrink the nasal mucosa before attempts at nasal intubation. Anesthesia of the airway increases patient comfort, decreases the response to intubation, and hence enhances the probability of success $^{21}$.

Because of the advantages of this procedure and its minimal limitations, the indication range for fiberoptic intubation should be broadly defined (Tables 2 and 3). This helps ensure the user is sufficiently experienced with this procedure, which is of particular benefit in emergency cases. The majority of anesthesiologists in the USA advocate awake flexible fiberoptic intubation as their first choice in patients with known or suspected cervical spine pathology, yet inexperience with this technique is a major concern of many practitioners $^{21}$.

Key points: Provided suitable technical equipment and use of the standard protocol, the fiberoptic intubation has no restrictions as to patient age and anatomical particularities. Moreover, fiberoptic intubation is 
not limited to a certain type of patient positioning. If a patient is to undergo fiberoptic intubation following an earlier unsuccessful attempt at laryngoscopic intubation, it is essential to switch to the fiberoptic procedure as early as possible. Otherwise, the swellings caused by repeated attempts at laryngoscopic intubation may cause complications, and in extreme cases thwart fiberoptic intubation completely ${ }^{21,22}$. However, even in experienced hands, flexible fiberoptic endoscopy takes longer to achieve intubation as compared to direct laryngoscopy and video laryngoscopy. It is expensive to buy, maintain and repair.

\section{Conclusions}

The incidence of difficult laryngoscopy and intubation has not changed in recent times. Persistent attempts at direct laryngoscopy are associated with low success rate and patient complications. The early use of alternative devices improves the likelihood of success in airway management and reduces the potential for patient injury. Alternative airway management devices are increasingly available to anesthesiologists, and there is expectation that anesthesiologists will possess the necessary skill to safely manage difficult airway with these alternative devices.

Available data suggest that new intubation equipment may play a crucial role in both predicted and unpredicted difficult or failed intubations. Ideally, such alternative devices should be available in all settings where tracheal intubation is performed. Most importantly, experience and competency with any of the alternative intubation equipment are critical for its successful use in any clinical setting.

\section{References}

1. Foregger R. Richard von Foregger, Ph.D., 1872-1960: manufacturer of anesthesia equipment. Anesthesiology. 1966;84:190-200.

2. Thong SY, Lim Y. Video and optic laryngoscopy assisted tracheal intubation - the new era. Anaesth Intensive Care. 2009;37:219-33.

3. Cook TM, Woodall N, Frek C; Forth National Audit Project. Major complications of airway management in the UK: results of the Fourth National Audit Project of the Royal College of Anaesthetists and the Difficult Airway Society. Part 1: Anaesthesia. Br J Anaesth. 2011;106:617-31. doi: 10.1093/ bja/aer058.
4. Smith CE, Sidhu TS, Lever J, Pinchak AB. The complexity of tracheal intubation using rigid fiberoptic laryngoscopy (WuScope). Anesth Analg.1999;89:236-9.

5. Healy DW, Maties O, Hovord D, Kheterpal S. A systematic review of the role of videolaryngoscopy in successful orotracheal intubation. BMC Anesthesiol. 2012;12:32. doi: 10.1186/1471-2253-12-32.

6. Azis MF, Dillman D, Fu R, Brambrink AM. Comparative effectiveness of the $\mathrm{C}-\mathrm{MAC}$ video laryngoscope versus direct laryngoscopy in the setting of the predicted difficult airway. Anesthesiology. 2012;116(3):629-36. doi: 10.1097/ ALN.0b013e318246ea34.

7. Mort C. Emergency tracheal intubation: complications associated with repeated laryngoscopic attempts. Anesth Analg. 2004;99(2):607-13.

8. Henderson JJ, Popat MT, Latto IP, Pearce AC. Difficult Airway Society guidelines for management of the unanticipated difficult intubation. Anaesthesia. 2004,59(7):675-94.

9. Cooper RM. Complications associated with the use of the Glidescope videolaryngoscope. Can J Anesth. 2007;54:54-7.

10. Niforopoulou P, Pantazopoulus I, Demestiha T, et al. Videolaryngoscopes in the adult airway management: a topical review of the literature. Acta Anaesthesiol Scand. 2010;54:105061. doi: 10.1111/j.1399-6576.2010.02285.x.

11. Walker L, Brampton W, Halai M, et al. Randomized controlled trial of intubation with the McGrath series 5 videolaryngoscope by inexperienced anaesthetists. Br J Anaesth. 2009;103(3):440-5. doi: 10.1093/bja/aep191.

12. Frova G. Do video laryngoscopes have a new role in the SIAARTI difficult airway management algorithm? Minerva Anestesiol. 2010;76:637-40.

13. Paolini JB, Donati F, Drolet P. Review article: Video-laryngoscopy: another tool for difficult intubation or a new paradigm in airway management? Can J Anesth. 2013;60:184-91. doi: 10.1007/s12630-012-9859-5.

14. Asai T. Video laryngoscopes: do they truly have roles in difficult airways? Anesthesiology. 2012;116:515-7. doi: 10.1097/ ALN.0b013e318246e866.

15. Fitzgerald E, Hodzovic I, Smith A. 'From darkness into light': time to make awake intubation with videolaryngoscopy the primary technique for an anticipated difficult airway? Anaesthesia. 2015;70:387-92. doi: 10.1111/anae.13042.

16. Kristensen MS. The LMA CTrach for awake intubation combines the features of the LMA Fastrach and the fiberoptic bronchoscope, but cannot replace this combination in all patients. Acta Anaesthesiol Scand. 2006;50:526.

17. Liem EB, Bjoraker DG, Gravenstien D. New options for airway management: intubating fibreoptic stylets. $\mathrm{Br} \mathrm{J}$ Anaesth. 2003;91:408-18.

18. Biro P, Battig U, Henderson J, Seifert B. First clinical experience of tracheal intubation with the SensaScope, a novel steerable semirigid video stylet. Br J Anaesth. 2006;97:25561. 
19. Hurford WE. A new view of laryngoscopy. BMC Anesthesiol. 2012;12:11. doi: 10.1186/1471-2253-12-11.

20. Rudolf C, Schnieder JP, Wallenborn J, et al. Movement of the upper cervical spine during laryngoscopy: a comparison of the Bonfils intubation fiberscope and the Macintosh laryngoscope. Anaesthesia. 2005;60:668-72.
21. Lipp M, Golecki N. Fiberoptic intubation - an introduction and review of case histories. Endo Press ${ }^{\mathrm{TM}}$ Tuttlingen, Germany, 2010.

22. Crobsy ET. Airway management in adults after cervical spine trauma. Anesthesiology. 2006;104;293-318.

\section{Sažetak}

\section{ALTERNATIVNI UREĐAJI ZA INTUBACIJU}

\section{B. Maldini, I. Hodžović i T. Goranović}

Macintoshov laringoskop je najčešće korišteni uređaj za intubaciju koji je prvi puta primijenio Foregger 1940. godine. Kasnije su uvedeni video i optički laringoskopi koji pomažu pri intubaciji u bolesnika s otežanim dišnim putem. Međutim, njihova rutinska uporaba nije široko prihvaćena u praksi. U ovom članku se sažeto iznose prednosti i nedostaci novih dostupnih uređaja koji pomažu tijekom intubacije u usporedbi s konvencionalnim laringoskopima. Dodatno se iznose razlozi za uporabu novih uređaja kod elektivnog i hitnog zbrinjavanja dišnoga puta.

Ključne riječi: Laringoskopi; Fiberoptička tehnologija; Video snimanje; Intubacija, intratrahealna 